\title{
MANUSCRITOS SOBRE LA EXPULSIÓN Y EL EXILIO DE LOS JESUITAS (1767-1815)
}

\author{
POR \\ InMACULADA FERNÁNDEZ ARRILlaGa
}

Universidad de Alicante

\begin{abstract}
RESUMEN
Repaso de los textos que se escriben sobre la controvertida decisión de expulsar a la Companfía de Jesús de Espafia. Se hace un recorrido por los principales textos jesuíticos, que tienen una clara intención de rebatir los argumentos establecidos por la publicista oficial sobre el tema.
\end{abstract}

\begin{abstract}
Revision of the texts about the disputable decision of expelling the Society of Jesus from Spain. The author studies the principal Jesuits texts, that have a clear intention of refuting the arguments referred by the official propaganda on the topic.
\end{abstract}

Cuando el P. Lorenzo Gilardi comenta la cantidad y pretensiones de los diarios escritos por miembros de su orden, asegura que «el género autobiográfico suscita particular interés porque constituye un momento de unión entre la Historia, la Literatura y la Teología, unión alcanzada gracias a una interpretación unitaria de la vida por parte del autons ${ }^{1}$. Habría que unir ese interés de los diaristas jesuitas a la voluntad de que sus escritos sirvieran para defender la causa

${ }^{1}$ Lorenzo GILARDI, S.I, «Autobiografia de los jesuitas en Italia (1540-1640). Historia e interpretación", Archivum Historicum Societatis lesu, 127, (1995), p. 4.

Actas del I Congreso de Historia de la Iglesia y el Mundo Hispánico

Hispania Sacra, 52 (2000) 
de la Compañia, pudiendo, si se diera el caso, ser utilizados contra sus detractores. Después de haber consultado más de una treintena de manuscritos, en los que los expulsos narran la expulsión de España y el destierro, no nos cabe duda de que fue ese interés apologético el que les movió a escribirlos; realizándolos en muy diversos modos, pero con una misma orientación y siguiendo un mismo patrón. Casi todos ellos se centran en la descripción de la forma en que les fue intimada la orden de destierro, en sus diferentes colegios o provincias, prosiguen con el viaje hasta Córcega y las dificultades padecidas en la isla y, en menor número, narran su establecimiento en las diferentes legacias de los Estados Pontificios en las que se instalaron.

Alonso Pérez de Valdívia ${ }^{2}$, catedrático de Teología del Colegio de Jaén en el momento de la expulsión, constató su exilio en dos obras: Comentorios para la historia del destierro, navegación y establecimiento en ltalia de los jesuitas andaluces y un compendio del anterior. Este fue uno de los escritos que un jesuita secularizado, el P. Vargas-Machuca, solicitó refutar al conde de Aranda en abril de 1773, por considerarlo injurioso contra el rey y sus ministros. Tradujo, solamente, la primera parte del diario del P. Pérez, pero Vargas afirmaba, en su introducción, que conocía la existencia de muchos más tomos manuscritos por este jesuita. El P. Pérez escribió, asimismo, unas Memorias para los Comentarios del destierro que resulta un compendio de la obra anterior, aunque sólo se conserva la parte que abarca desde 1784 hasta $1790^{3}$. Por otra parte, mientras Alonso Pérez se encontraba en Pesaro, en noviembre de 1783, recopiló y preservó la narración del P. Bernardo Recio, que trataremos al referimos a la Provincia de Quito.

Otro de los jesuitas andaluces, Rafael de Córdoba ${ }^{4}$, escribió la Relación inédita del destierro de los padres jesuitas de Andalucia en 1767. Comienza este escrito el 25 de marzo de ese año, describiendo la forma en la que les intimaron la Pragmática de expulsión. Explica las temporalidades que registraron y el dinero que se halló en cada casa; así como el trato que recibieron los novicios y lo que les ocurrió a los irlandeses e ingleses que había en el Colegio de las

\footnotetext{
2 Alonso Pérez nació el 24 de septiembre de 1723 en Córdoba. El 2 de mayo de 1767 embarcó, en el Puerto de Santa María, a bordo del «La Paz», bacia Civitavechia. En 1773 residía en Rávena y, tras la extinción de la Compafía, fue encargado por el Senado de Pésaro la reforma de las escuelas públicas. Rector del Seminario de Gubbio, regresó a Espafía en 1797, muriendo en Sevilla en 1799. A.G.S. Marina, Leg. 724. Agradecemos estos datos al profesor Giménez López.

${ }^{3}$ De esta obra, el tomo $\mathrm{XX}$, referido a 1777, lo custodia el Archivo Histórico de la Provincia de Toledo (A.H.P.C.T.S.I.), E-2; 1, 9.4 (Leg. 1395.10), y los tomos X y XI se localizan en la Biblioteca Nacional de Madrid (B..N.): Ms. 20.550

4 El P. Córdoba era rector del Colegio de Cádiz en el momento de la expulsión, y fue el superior de los jesuitas andaluces establecidos en Calvi. M. LuENGo, Diario de la expulsión de los jesuitas, T. I, p. 167, Archivo Histórico de Loyola (A.H.L.), Documentos de jestitas del s. XVIII, baldas 4 y 5.
}

Actas del I Congreso de Historia de la Iglesia y el Mundo Hispánico Hisparia Sacra, $52(2000)$ 
Becas. Narra, muy sucintamente, la situación de los jesuitas más ancianos y lo que ocurrió con los colegiales, y da noticia de la llegada a Sevilla de los jesuitas que faltaban de algunas ciudades extremeñas junto con los de Córdoba y Carmona. Este relato no ocupa más de quince páginas, contiene extensas anotaciones al margen, la mayoría escritas con posterioridad al diario del viaje ${ }^{5}$, y tiene un final muy significativo que podemos enmarcarlo dentro de esa política de invitación a que quedara constancia de la expulsión. El relato del P. Córdoba acaba el día dos de mayo en el puerto de Jerez, advirtiendo que quedaron en tierra treinta sujetos, enfermos o ancianos, y escribe: «víctimas de una horrible inquietud. Hablará por nosotros uno de ellos», tras estas letras, aparece una copia del diario del P. Tienda ${ }^{6}$, que era profesor de Filosofia del Colegio de San Hermenegildo de Sevilla en 1767. Su Diario de la navegación de los jesuitas de la Provincia de Andalucia desde el Puerto de Santa Maria y Málaga hasta Civitavecchia, no nos detenemos en él porque ha sido estudiado, en profundidad, por los profesores Giménez y Martínez ${ }^{7}$ y José A. Ferrer Benimeli ${ }^{8}$. Se encuentra custodiado en el Archivo Municipal de Sevilla ${ }^{9}$ y otra copia es la ya aludida del Archivo de Toledo ${ }^{10}$.

Los autores referidos en el párrafo anterior y Medina ${ }^{11}$, estudiaron también la obra del P. Cano ${ }^{12}$, sacerdote del mismo Colegio sevillano que tituló su obra: Viaje de los últimos jesuitas andaluces y descripción de Ajaccio, se encuentra

${ }^{5}$ Incorpora noticias de 1769 , y algunas notas nos conducen a documentación procedente del Archivo Municipal de Sevilla (A.M.S.), Leg. Jesuitas, 34; véase la p. 11-bis de este manuscrito en A.H.P.C.T.S.I, M-335.

6 Diego de Tienda era natural de Baena, en Córdoba. Había nacido el 13 de junio de 1726 y era profeso de Cuarto Voto desde 1759. Embarcó en el Puerto de Santa María en el navio sueco "General Vaucaulbes" el 2 de mayo de 1767 rumbo al destierro, en A.G.S., Marina, Leg. 724: Relación de los individuos del Orden de la Compañia que se han hoy día de la fecha a bordo del navio sueco "General Vancaulbes Puerto de Santa Maria, 2 de mayo de 1767. Agradecemos estos datos al Profesor Giménez López.

7 E. GimÉnez López y M. Martanez Goms, «Los diarios del exilio de los jesuitas de la Provincía de Andalucias, en Revista de Historia Moderna, Anales de la Universidad de Alicante, 13-14, Alicante, 1995, pp. 211-254

8 José A. Ferrer Benimeli, "Córcega vista por los jesuitas andaluces expulsos», Homenaje a Francisco Aguilar Piñal, C.S.I.C., Madrid, 1996.

9 Archivo Municipal de Sevilla, (A.M.S.), XIX, «Papeles del Conde de Águila».

10 A.H.P.C.T.S.I., M-335. A partir de la p. 17.

"Francisco de Borja MEDINA, «Ocaso de una provincia de fundación ignaciana: la Provincia de Andalucía en el exilio (1767-1773)», Archivo Teológico granadino, 54 (1991), pp. 5-90.

t2 Marcos Cano había nacido el 9 de febrero de 1730 en Begijar, Jaén y entró en la Compañía el 23 de febrero de 1750 , profesando el Cusarto Voto el 3 de diciembre de 1767. En Cartagena embarcó en el navío holandés «Catalina Polonia», el 9 de octubre de 1767. Se fugó de Córcega el 5 de octubre de 1768, secularizándose el 23 de octubre de ese mismo afio; desde entonces, y hasta después de la extinción de la Companía, vivió en Roma. 
en el Archivo Municipal de Sevilla ${ }^{13}$, donde sólo se conservan cinco folios de su escrito, concretamente los referidos a su llegada a Ajaccio. El P. Cano comentaba, escuetamente, las incidencias del viaje que realizaron a Córcega, desde su salida de Cartagena el 6 de octubre de 1767, hasta su llegada a Ajaccio, ciudad en la que desembarcaron el día 5 de noviembre de ese mismo afío. Los pocos folios manuscritos que se conservan en este archivo intentan describir la ciudad y las características que más llamaron la atención al jesuita, centrándose en el aspecto y vestimenta de los hombres y las mujeres de la villa corsa, ninguno de los cuales sale bien parado, en esta breve y negativa descripción de la población de la isla.

Señalaremos por último, relativo a la Provincia de Andalucía, dos manuscritos, uno inédito, titulado Diario breve de la navegación a Italia ${ }^{14} \mathrm{y}$ otro escrito por Diego Tienda. El primero es un sintético cuaderno de bitácora, realizado durante la navegación desde el Puerto de Santa María, en mayo de 1767, hasta su desembarco en Calvi, el 14 de julio. Los comentarios son escuetos y referidos, fundamentalmente, al tiempo que hacía y a los acontecimientos propios de la singladura, por lo que aporta poco en cuanto a la situación de los expulsos ${ }^{15}$. El segundo, el Diario de la navegación de los jesuitas de la Provincia de Andalucía desde el Puerto de Santa María y Málaga hasta Civitavecchia que escribió el P. Tienda, descansa en el Archivo Municipal de Sevilla ${ }^{16}$, encontrándose una copia parcial de este diario en el Archivo de Alcalá de Henares ${ }^{17}$. Es un escrito comentado por los profesores Giménez y Martínez ${ }^{18}$, y posteriormente, por Ferrer Benimeli ${ }^{19}$.

De la Provincia de Castilla destaca la conocida obra del P. Manuel Luengo, no sólo por la extensión del escrito (su diario abarca los 49 años del exilio), sino también por la cantidad de papeles que recoge en su conocida Colección de Papeles Varios, comprimida en veintiseis voluminosos tomos. Se trata de una obra realizada con fines apologéticos, propensa al subjetivismo favorable a la leyenda blanca sobre la inocencia de los jesuitas y muy útil por la cantidad de datos que aporta ${ }^{20}$. Por otra parte, tenemos constancia de tres manuscritos rela-

\footnotetext{
${ }^{13}$ A.M.S., "Papeles del Conde de Aguilap. Jesuitas de Sevilla. … 44.

14 Transcrito y comentado por los profesores Giménez López y Martínez Gomis, en el artículo mencionado con anterioridad.

is En A.M.S., «Papeles del Conde del Águila», ss. XI-XII, 41.

16 A.M.S., Papeles del conde de Águila, s. XIX.

17 Hay una copia que comienza en la página 17 del escrito del P. Córdoba. AHPCTSI, M-335.

${ }^{18}$ E. GMÉNEZ LÓPEZ Y M. MARTINEZ GOMS, op. cit.

19 José A. FERRER BENMELI, op. cit., Madrid, 1996.

${ }^{20}$ La obra del P. Luengo ha sido objeto de numerosas publicaciones, en la actualidad la autora de este artículo realiza su tesis doctoral sobre la vida y obra de este prolifico diarista expulso.
} 
cionados con el P. Isla: una, su famoso Memorial $^{21}$ en el que se da cuenta, no sólo de las peripecias de la Provincia castellana, también de las otras tres españolas: Anđalucia, Aragón y Toledo, copiado por el P. Luengo en su segundo tomo de la Colección, y en la que incluye una serie de comentarios, a pie de página, sobre lo que narra el P. Isla. Una copia de este memorial, aunque parece un borrador, ya que carece de la cuidada redacción del anteriormente citado, es de Gerónimo Labastida ${ }^{22}$; y otro escrito, sin firma, pero atribuido al P. Isla, es el igualmente titulado Viaje de los jesuitas en su expulsión que, sobre este mismo tema se conserva, como el anterior, en el Archivo de la Provincia de Toledo, y que incluye un prólogo del P. Uriarte ${ }^{23}$.

El jesuita castellano, José Cortázar ${ }^{24}$, perteneciente al Colegio de Santiago, fue el autor de otro diario del extrañamiento, que comenzó a escribir en 1767 y lo finalizó cuando se encontraba establecido en Bolonia. Se trata de una relación no titulada sobre el exilio. Esta estructurada en cuidados capítulos, comenzando con el arresto en aquel colegio gallego, narrando después el embarque en Coruña, la travesía y llegada a Calvi, su estancia en la isla, la muerte de Clemente XIII y la llegada de Ganganelii, la convivencia en Bolonia y la detención del P. Isla en 1773. A partir de aquí el diario queda cortado, por lo que no podemos afirmar si hubo o no una continuación. El tomo que hemos localizado, esta compuesto por más de doscientas páginas, numeradas con posterioridad y depositado en el Archivo de la Provincia de Toledo ${ }^{25}$.

Dentro de esta tradición diarista, incluiremos al padre Faustino Arévalo, que cuando se restableció la Compañía de Jesús en España preparó un texto en el que narra la actividad de los expulsos, al volver a Loyola, desde el 19 de abril

\footnotetext{
21 José Francisco IsLA, Memorial en nombre de las cuatro Provincias de España de la Compañía de Jesuis a S. M. el Rey D. Carlos III, impreso en Madrid, en 1882. El profesor Giménez López ha preparado la teedición critica de este documento, incluyendo los comentarios que realizó el P. Luengo sobre una copia de este Memorial. José Francisco IsLA, Historia de la expulsión de los jesuitas.., Estudio introductorio y notas de Enrique Gimenez, Instituto de Cultura (Juan Gil-Albert», Diputación Provincial de Alicante, 1999.

22 "Viaje de los Jesuitas en su expulsión», A.H.P.C.T.S.I., C-88 (210).

${ }^{23}$ A.H.P.C.T.S.I., C-230 (210).

${ }^{24}$ Habia nacido, este P. Cortazar, el 1 de abril de 1749 en Oñate, y terminó sus estudios de Filosofia en septiembre de 1769, siendo alumno del P. Luengo en la casa Bianquini de Bolonia, to que nos inclina a creer en cierto influjo del maestro en su discípulo. En 1909, José Cortazar, se negó a realizar el juramento a la Constitución de Bayona y al rey José Bonaparte, pero días después lo prestó en Bolonia, donde era confesor de las monjas carmelitas de aquelia ciudad. Sabemos también que tenía una sobrina casada con Gutiérrez de la Huerta, fiscal del Consejo de Castilla, que presionó para que se acelerara el restablecimiento en Esparia de la Compañia de Jesús en 1815. Murió en Loyola, de donde era Rector, el 12 de marzo de 1826.

${ }^{25}$ A.H.P.C.T.S.I., M-136.
} 
de 1816 hasta el verano de $1820^{26}$, y que se custodia en el archivo de esa provincia ${ }^{27}$. Aquí también puede estudiarse el diario del P. Diego de Goitia, jesuita vizcaino que escribió un escueto relato de sus viajes, comenzando a referir el primero que hizo, hacia Bilbao en 1750, para ingresar en la Compañía de Jesús, hasta el que le llevó a Loyola en octubre de 1823, donde sería Rector y donde moriría el 21 de agosto de 1829. Se trata de un reducido escrito en el que sólo quedan reflejadas las fechas y los lugares por donde pasó en sus desplazamientos, pero muy interesante para reconstruir gran parte de su vida, así como todos los itinerarios que realizó mientras estuvo exiliado y en su periplo de retorno ${ }^{28}$.

No se quedaron atrás los novicios castellanos, a la hora de redactar su viaje al exilio. Isidro Arévalo ${ }^{29}$, escribió en Calvi, una relación de todas las aventuras de estos novicios castellanos. Su Relación de lo que pasó con los Novicios de la Compañia de Jesús de la Provincia de Castilla en su expulsión fue uno de los documentos que utilizó el padre Isla para elaborar su Memorial a Carlos $\operatorname{III}^{30}$ y en ella incluyó una serie de relaciones con los nombres y algunos datos de interés sobre los novicios que realizaron este viaje ${ }^{31}$. Se conserva la narración de otro novicio de la Provincia de Castilla, Vicente Antonio Calvo que cuenta su viaje desde que saliera del Colegio de Villagarcía hasta la extinción de la Compartía en $1773^{32}$. Comienza su narración, sin título, haciendo una breve autobiografia y describiendo, lacónicamente, el viaje y la llegada a Córcega. Dedica pocas líneas a su estancia en Bolonia. Retratando su ordenación sacerdotal en 1772 y la sorpresa que causó a los expulsos la extinción de la Compañía y los apresamientos de algunos de los jesuitas españoles, tras la orden abolicionista, entre ellos el P. Isla. En total son siete páginas, escritas con letra clara y narración meditada que, una vez más y, sabiendo que el $P$. Luengo estaba entre sus

${ }^{26}$ En L. Frías, Historia de la Compañia de Jesús en su Asistencia moderna de España, Razón y Fe, T. II, Madrid, 1944, p. VII.

${ }^{27}$ A.H.L., 1-4-3. Tomo III. Doc. 1/Ord. Asj n. 819.

${ }^{28}$ Diario y viajes del P. Diego de Goitia, S.I.(I739-1824). A.H.L., escritos 9/7. Agradecemos la localización de este documento al $P$. José Ramón Eguillor y a Olatz Berasategui, quienes realizaron una exhaustiva búsqueda, por encargo nuestro, en el mencionado archivo azpeitarra.

${ }^{29}$ Isidro Arévalo, nacido el 15 de mayo de 1745 en Cabezas del Pozo, Ávila, era el mayor de los novicios del Colegio de Villagarcia de Campos, y fue su guía en el viaje que les llevó, desde que los separaron de los padres en Torquemada, hasta su reencuentro en Santander, desde donde partieron con ellos hacia el destierro

${ }^{30}$ M. LuENGo, Diario de la expulsión de los jesuitas de España..., A.H.L., T. I, p. 154.

${ }^{31}$ Se encuentra copia en M. LuENGo, Colección de Papeles Varios, T. 1, pp.51-119.

32 EI P. Calvo nació el 30 de junio de 1745 en Iglesario, en Santiago de Compostela. Fue uno de los novicios que se unió a la Provincia de Castilla en Santander para embarcar hacia Italia, posteriormente, firmaría el Memorial que los novicios enviaron a Espafia solicitando pensión tras la extinción. M. LuENGo, Colección de Papeles Varios, T. 1, p. 120 y Diario, T. V, p. 15.

Actas del I Congreso de Historia de la Iglesia y el Mundo Hispánico Hispania Sacra, 52 (2000) 
profesores, nos mueve a pensar que está realizada gracias al ascendiente que tuvieron en el novicio sus superiores ${ }^{33}$.

En lo que respecta a la Provincia de Aragón, hay referencias de un diario, elaborado por el P. Francisco Javier Borrull, en relación con el restablecimiento de la Compañía en Valencia, en 1815, de características muy similares al referido anteriormente de Faustino Arévalo, para la Provincia de Castilla, y de otra obra anónima, que, no sabemos cuando comienza pero que finaliza el $11 \mathrm{de}$ abril de 1817, con la muerte del P. Masdeu, ambas reseñadas por el P. Lesmes Frías $^{34}$. Por su parte, Vicente Olcina, alicantino y perteneciente también a provincia aragonesa, escribió unas memorias que encuademó en cuatro volúmenes: el primero de ellos ${ }^{35}$ lo dedicó a describir el viaje y el establecimiento de los jesuitas en Italia. En el segundo, relata lo acontecido desde el momento en que comenzaron a vivir en Ferrara hasta la muerte de Clemente XIV. La tercera parte abarca desde entonces hasta 1782 y, el último volumen, lo dedicó a Varios y curiosos sucesos concernientes a la presente persecución de la Compañia de Jesús, a los jesuitas españoles desterrados en Italia y a otros puntos de la Historia Eclesiástica del septimo y octavo año del Pontificado de Pio VI. Completó este trabajo con dos obras más sobre la misma materia: Miscelánea sobre la expulsión y abolición de la Compañía, precedida de un índice alfabético de cosas y otro de capitulos, y otra titulada Selectas profecías, visiones y casos concernientes a la presente persecución de la Compañía de Jesús, y al arresto y destierro de los jesuitas portugueses y Españoles ${ }^{36}$. Hemos de constatar la tremenda semejanza que muestra la obra del P. Olcina con la del P. Luengo, tanto en lo referente a la estructura de las memorias de ambos, como en su contenido, y en los puntos de vista que exponían. Además, el P. Vicente Olcina ${ }^{37}$ escribió otra obra: Semejanza de la Causa de los Jesuitas con la de su Capitán Jestís, en la que sólo el título, refleja la misma manera de pensar que plasmó Luengo en su Diario. Tememos que toda la obra del P. Olcina, que se conservaba en el

\footnotetext{
${ }^{33}$ A.H.P.C.T.S.I., M-136.

${ }^{34}$ L. Frias, op. cit, Vol. I, p. VIII.

35 Titulado: Festiva relación de los trágicos sucesos acaecidos a los Jesuitas de la Provincia de Aragón desde el dia de su Arresto hasta el dia de su establecimiento en la ciudad de Ferrara.

${ }_{36}$ En Adolfo Dominguez MolTó, Vicente Olcina, fabulista Luis Olcina, misionero, Caja de Ahoros Provincial de Alicante, 1984, pp. 37 y ss.

37 Vicente Olcina procedia de un pueblo de La Montaña de Alicante, Gorga, donde nació en 1731; a los dieciséis años ingresó en el noviciado de Tarragona, y se ordenó sacerdote en Valencia once afios más tarde. Fue profesor de retórica en Tortosa y, después, en Onteniente. La expulsión le sorprendió en el Colegio de Alicante, donde era profesor de Teologia, y en donde hizo su profesión religiosa, el 2 de febrero de 1767. Además de por su labor como diarista, al P. Olcina se le conocía como fabulista, genero que cultivó, sobre todo, durante el exilio italiano y del que se conserva una antología publicada en Valencia en 1800. Murió en Roma en 1809.
} 
Archivo de Sarrià, desapareciera tras la Guerra Civil española, concretamente en 1939; afortunadamente, podemos encontrar parte de sus memorias en el trabajo de Nonell sobre el P. Pignatelli ${ }^{38}$. Otro alicantino, Juan Andrés, durante su estancia en Córcega, escribió un comentario sobre los acontecimientos que rodearon a los jesuitas en la isla, trabajo que, según Domínguez Moltó, quedó inédito y seguramente perdido ${ }^{39}$. Por su parte, el que fuera el último Provincial de Aragón, el P. Blas Larraz, nos dejó sus memorias del exilio en una obra que titulo De rebus Sociorum Provinciae Aragoniae Societatis Jesu, ab inidicto ipsis ex Hispania exsilio usque ad Societatis abolitionem Commentarii tres ${ }^{40}$. Fue escrita en tres momentos diferentes: el primero en 1767, el segundo en 1785 y el último un año más tarde y permanece inédita aunque no por ello desconocida, siendo publicada parte de ella en castellano por José Benitez en un muy documentado artículo ${ }^{41}$.

En cuanto a las provincias de ultramar, concretamente con respecto a la única de la Asistencia espafiola en Asia: la Provincia de Filipinas, contamos con dos manuscritos: el escrito por Pedro Caseda y el diario de Francisco Javier Puig ${ }^{42}$ titulado Arresto y viaje de los jesuitas de Filipinas. Este escrito fue estudiado por Ernest Burrus ${ }^{43}$, por Rubén Vargas ${ }^{44}$, y mencionado en repetidas ocasiones por Cushner, en su obra dedicada a los jesuitas filipinos ${ }^{45}$, también Miquel Batllori lo analizó en su aspecto linglístico ${ }^{46}$ y recientemente, ha sido citado por Santiago Lorenzo ${ }^{47}$. El escrito de Francisco Javier Puig aparece publicado y traducido al inglés en la obra a la que hemos hecho referencia de Cushner. Este diario trata del destierro de los jesuitas de la Provincia de Filipi-

\footnotetext{
38 Javier NoneLL, VP. José Pignatelli y la Compañia de Jesús en su extinción y restablecimiento. Manresa, 1893-1894. 2 vols.

${ }^{39}$ A. DOMfNGUEz Molró, op. cit., p. 48 (27).

${ }^{40}$ Biblioteca de la Universidad de Valencia Ms. 906. Véanse también las localizaciones que ofrece Miquel Batllori en Història, classicisme i filosofia al segle XVIII: Gustà, Pou i Masdèu, Tres i Quatre, València, 1998.

41 Josep Benitez I RIERA, «La història dels jesuïtes de la 'Provincia d'Arago" desterrats d’Espanya per Carles III, escrita pel pare Blai Larrazs, Anuari 1992-1993 de la Societat d'Estudis d'Història Eclesid̀stica Moderna i Contemporània de Catalumya, Tarragona, 1997, pp. 243-279.

${ }^{42}$ También Puche.

43 Emest BuRRUS, «Francisco Javier Alegre, Historian of the Jesuits in New Spain", Archivum Historicum Societotis lesu, XXII, (1953), pp. 439-509.

${ }^{44}$ E. VARGAS UGARTE, Manuscritos peruanos en las bibliotecas y archivos de Europa y América. En Nicholas CUSHNER, Philippines Jesuits in exile, 1964, p. 45.

45 Nicholas CusHNER, op. cit., pp. 41 y ss.

46 En Emest BuRRUs, op. cit., p. 495.

47 Santiago Lorenzo, «La expulsión de los jesuitas filipinos: un ejemplo de disputa por el poder político", Revista de Historia Moderna, Anales de la Universidad de Alicante, n. ${ }^{\circ} 15,1996$, pp. 179 -
} 200 .

Actas del I Congreso de Historia de la Iglesia y el Mundo Hispánico Hispania Sacra, 52 (2000) 
nas, describiendo la instalación en las islas de los jesuitas desde 1580 , año en el que llega san Francisco Javier a la isla de Mindanao en su labor evangelizadora. Desde entonces hasta 1767 , realiza un corto recorrido sobre el avance de las misiones en aquellas islas, para pasar después a describir, detalladamente, la intimación de la pragmática de expulsión, las medidas tomadas para el embarque de los regulares y su salida hacia la península Ibérica, desde donde viajarían hacia Italia. A partir de ahí, el diario se convierte en un cuaderno de viaje en el que va narrando las peripecias pasadas hasta arribar al puerto gaditano, donde llegaron en octubre de 1770, y de allí hacia Italia. Es un diario escrito después de que pasaran los hechos, posiblemente cuando ya estaban en los Estados Pontificios y en el que, al final, incluye el estado en que quedaron las misiones en Filipinas, haciendo mención a las profecías sobre desastres en las islas a causa de la salida forzosa de los miembros del Instituto de san Ignacio. Nicholas Cushner cita, en la obra referida anteriormente, la existencia de cinco copias del Diario de Puig, la primera custodiada en Loyola ${ }^{48}$, otra en Florencia ${ }^{49}$ y tres más en el Archivo de la Provincia de Aragón ${ }^{50}$. El hecho de que se realicen tantas copias de estos diarios deriva, como ya hemos mencionado, del interés por mantener estas narraciones, no sólo por su importancia histórica, sino por su aspecto ensalzador de aquellos expulsos. Encontramos en cada copia una serie de errores diferentes, lo que podría indicarnos que los copistas fueron varios y en diferentes épocas. Por su parte el escrito del pamplonica P. Pedro Caseda, titulado Carta de un español jesuita, en la que se contiene un anécdota que declara el motivo general de las presentes novedades, venía a ser una conversación en la que el Seffor Galván, oidor en Manila declaraba al jesuita filipino, que el destierro de los jesuitas de Espaffa era el proyecto que tenían los golillas para arruinar el gobierno monárquico. La escribió en 1785, aunque los hechos que narraban se referían a mayo de 1769 , en Manila ${ }^{51}$.

América ha sido, tradicionalmente, la que ha ofrecido a la historia de la Compańía diarios más variados ${ }^{52}$. Desde su implantación en aquellas tierras, los

\footnotetext{
48 A.H.L.: IV-3-6. Doc.10 Ord. Asj n. ${ }^{0}$ 2114, Destierro de los Jesuitas de la Provincia de Filipinas.

49 Biblioteca Nazionale de Firenze, N.A. 151, Vol. III, pp. 833-916 (33a-74b).

50 Sobre las tres copias del Diario del P. Puig, custodiadas en el Archivo de San Cugat podemos decir que una está bajo el título de Destierro de los Jesuitas de la Provincia de Filipinas, en el Legajo titulado «Documentos de le época del extraf́amiento de la Companía de Jesús en Filipinas", E-1-d,5 y escrita con letra del siglo XIX, de entre 1860 y 1890 , siendo una copia exacta de la de Loyola aunque modernizada su caligrafia. La segunda se encuentra en un legajo titulado "Algunas excursiones de los misioneros en las Islas Filipinas» E-II-B, 89, también sacada de la versión que se encuentra en Loyola. La tercera especifica literalmente que es copia de la del Archivo azpeitarra y se encuentra en la Colección Pastells, CVI, 1769-1774, ff. 82-89.

${ }_{31}$ M. LuEngo, Colección, T. 20, Pág. 96 y transcrita por NoneLL, op. cil. T. I, pp. 231-239.

52 Véase a modo de ejemplo los que recopila en su El Paraguay Católico, Sánchez Labrador, Real Academia de la Historia, Cortes, 9/2276.
} 
jesuitas cumplieron su tarea de cronistas de los viajes, exploraciones y experiencias que vivieron, elaborando documentos de singular importancia y muy variado interés ${ }^{33}$; de hecho, las crónicas jesuíticas han sido consideradas fuentes primordiales para el estudio de la historia novohispana ${ }^{54}$. Esta tradición la siguieron los expulsos legándonos más de una docena de escritos sobre sus vivencias en los viajes del destierro. En La Provincia de Quito tenemos al P. Isidro Losa ${ }^{55}$ que narra en su diario la forma en que fue intimada la Pragmática de expulsión en el Colegio Máximo de Quito y el viaje de los padres de esta Provincia hacia el exi$10^{56}$. Fue escrito cuando ya estaba instalado en Rávena y se centra en la pura descripción de los hechos, destacando los momentos más duros de los viajes y apuntando, meticulosamente, los nombres de aquellos que fueron falleciendo en el camino. Esta es una constumbre que observamos en muchos de los escritos estudiados, suponemos que la finalidad era la futura elaboración de las correspondientes cartas de edificación que, a la muerte de los regulares, suelen escribirse. Quizá la obra más conocida, en cuanto a recopilación de necrológicas de jesuitas expulsos sea la de Juan Luis Maneiro, De vitis aliquot mexicanorum ${ }^{57}$, escrita en Bolonia entre los afios 1791 y 1792, donde quedaron reflejadas las biografias de treinta y cinco de sus compañeros en el exilio.

Menos extensa, pero también significativa, es la relación que nos legó el $P$. Bernardo Recio ${ }^{58}$. Se trata de un escueto manuscrito en el que narra el viaje que realizó desde Gerona hasta Italia, junto al otro procurador de su Provincia: Tomás Larrain. Viajaban hacia Roma, procedentes de Quito, sin sospechar la sorpresa que se avecinaba, y es que habían elegido una mala fecha para dejar su provincia quiteña. El día 3 de abril de 1767, ya en España, de camino a la frontera francesa y sin dar crédito a sus ojos, veían cómo los soldados cercaban el colegio de sus hermanos, los jesuitas de Gerona. Una serie de coincidencias for-

53. Véase el capítulo Diarios inéditos de viaje en la obra titulada José Sánchez Labrador y los naturalistas Jesuitas del Río de la Plata, VV.AA., MOPU, Madrid, 1989, pp. 286-290. Queremos agradecer al profesor José Manuel Rubio Recio la noticia de esta obra y de otras publicaciones relacionadas con los jestuitas expulsos de América.

${ }^{54} \mathrm{M}^{2}$ del Carmen EsPINOSA, «La palabra conquistadora. Las crónicas jesuitas sobre el noroeste novohispano", Anales de Literatura Española, Universidad de Alicante, N. 13 (1999), p. 169.

55 El P. Losa nació el 20 de mayo de 1725 y murió en Roma el 3 de marzo de 1782.

56 Los jesuitas quiteños del extrañamiento, prólogo de Aurelio Espinosa, Puebla, 1960. En Salud MoReno Alonso, «Bucareli y el paso de los jesuitas por Cuba camino del destierto», Actas del Congreso Internacional de Historia, Córdoba, 1993, pp. 197-202. Aunque CusHNER cita otro escrito de este jesuita quiterio en la obra citada sobre los filipinos.

57 Juan Luis MANEJRo, Vidas de algunos mexicanos ilustres, Universidad Nacional Autónoma de México, Méjico, 1988. Bernabé NaVarRo, Vidas de mexicanos ilustres del siglo XVIII, Universidad Nacional Autónoma de México, Méjico, 1989. Agradecemos al profesor José Carlos Rovira su amibilidad al cedernos estas obras.

58 Esta relación fue transcrita por NONELL en la obra citada, T.I., pp. 219-224.

Actas del I Congreso de Historia de la Iglesia y el Mundo Hispánico

Hispania Sacra, 52 (2000) 
zaron su detención en Cataluña: estos padres americanos eran procuradores de colegios en Quito por lo que no podían salir hacia el exilio con los jesuitas aragoneses; pero cuando pretendieron hacerlo con los procuradores de los colegios de Aragón, se lo prohibieron, ya que debían esperar a que llegaran sus compañeros de Quito. Mientras tanto fueron detenidos, y a los seis meses de arresto moría el P. Larrain. Los jesuitas de la Provincia de Quito, que nunca pasaron por Aragón en el viaje hacia el destierro, nada supieron de lo que les había ocurrido a sus dos procuradores. El sobreviviente P. Recio, sufriría una prisión de siete años; hasta que en 1773, al ser extinguida la Compañía, consiguió permiso para proseguir el fatídico viaje y pudo embarcar hacia Roma en 1776. Durante aquellos affos de arresto, su hermano Clemente, perteneciente a la Provincia de Castilla, había hecho correr la voz de la desaparición de su familiar ${ }^{59}$, ya que desconoció su paradero hasta 1771, afio en el que recibió una carta de Bernardo en la que le comentaba parte de su odisea ${ }^{60}$. No queremos dejar la Provincia de Quito sin referimos al conocido escrito del P. Velasco Historia del Reino de Quito, en esta obra, recopilada en cinco volúmenes, trata la expulsión y parte de sus experiencias en el destierro en el apartado que tituló Colección de poesias varias hechas por un ocioso en la ciudad de Faenza, donde incluye los percances de otros quince jesuitas quitefíos ${ }^{61}$ y el Diario de un misionero de Mainas, escrito por el $P$. Manuel Uriarte ${ }^{62}$.

Siguiendo con las provincias americanas, conocemos algunos escritos relacionados con la de Méjico, dos de ellos fueron publicados en 1944 con un prólogo del P. Cuevas: los trabajos de Antonio López Priego ${ }^{63}$ y el de Rafael de Celis $^{64}$. Un tercero, de Bernardo Middenfdorf ${ }^{65}$ titulado Misionero de Movas,

\footnotetext{
${ }^{59}$ El P. Luengo le suponía en algún convento de Gerona, Diario, T. III, p. 199.

${ }^{60}$ M. Luengo, Diario, T. V, p. 81.

${ }^{61}$ En Nicholas CUSENER, op. cit., Roma, 1964.

62 F. Esteve BARBA, Historiografia indiana, Gredos, Madrid, 1992, p. 435.

63 Antonio Priego fue sacerdote del Colegio de San Francisco Javier de Puebla, ciudad en la que nació el 8 de febrero de 1730. Jesuita desde el 3-IV-1751 y profeso de cuarto voto. Embarcó en Veracruz en el bergantín "San Francisco Javien", Ilegando a La Habana en noviembre de 1767. Fue internado enfermo en el Convento de los Bethlemitas de La Habana y volvió a embarcar en esta capital en diciembre de aquel mismo año, con destino a Cádiz. En 1773, residia en la ciudad de Bolonia. A.G.S., D.G.T., Inventario 27, Leg. 1. Agradecemos estos datos al profesor Giménez. Véase sobre este autor: Tesoros Documentales de México, en Salud Moreno Aconso, op. cif., pp. 197-202.

${ }^{64}$ Era estudiante del Colegio de Tepozotlan. Embarcado en Veracruz en la Fragata San Miguel, alias «El Bizarro" con destino El Puerto de Santa María. Secularizado. Residia en Bolonia en 177. Agradecemos estos datos al profesor Giménez. Véase sobre este autor: Tesoros Documentales de México, en Salud MORENO ALONSO, op. cit., pp. 197-202.

65 Sacerdote de las misiones de Sonora. Nacido el 14-II-I723. Embarcado en Veracruz en el Bergantín francés «Aventurero», que llegó a La Habana el 5-V-1769. Datos proporcionados por el profesor
} Giménez. 
Sonora, retrata la situación de aquella zona desde 1758 hasta el destierro de $1767^{66}$. Destaca también la obra de Francisco Javier Alegre sobre la Compañía de Jesús en Nueva España ${ }^{67}$, la de Francisco Javier Clavijero que escribió dos narraciones referidas a la Compañía, una de la Provincia de Méjico y otra sobre California $^{68}$, sin olvidar otra historia sobre la ciudad de Méjico escrita por el P. Andrés Cavo de esa provincia ${ }^{69}$. Hay referencia de otros tres diarios de jesuitas pertenecientes a de la Provincia de Perú: el de Francisco Larreta ${ }^{70}$, las memorias de Juan José Godoy ${ }^{71}$ y otra anónima que se conserva en Florencia ${ }^{72}$. De autor desconocido es también la relación del Viaje a Italia de los misioneros desterrados de Santa Fe en $1767^{73}$. Perteneciente a esa misma Provincia de Santa Fe, Vicente Sanz, novicio coadjutor del Colegio de Tarija en el momento de la expulsión, y que decidió seguir voluntariamente a los padres en su exilio ${ }^{74}$; escribió una obra titulada La Inocencia de la Compañia justificada, Anécdotas hasta la extinción $n^{75}$, mientras estaba desterrado en Urbino ${ }^{76}$. Existen otras dos obras anónimas relacionadas con este interés laudatorio: una el Discurso histórico-crítico de la expulsión de los Jesuitas de los reinos de España en $1767^{77}$ y otra Relación del viaje de mar de diecinueve jesuitas que salieron de Roma a los 20 de octubre y llegaron a Barcelona después de varias averias el dia 5 de diciembre de $1815^{78}$.

66 En Nicholas CUSHNER, op. cit., 1964.

${ }^{67}$ E. BuRrus y F. ZubillaGa, Francisco Javier Alegre, Historia de la provincia de la Compaĥla de Jesuis en Nueva España, Roma, 1956. Véase también F. GoNzÁlez DE Cossto, Crónicas de la Compañia de Jesús en la Nueva España, Universidad Nacional Autónoma de México, Méjico, 1995, pp. 192-198.

${ }^{68}$ F. EsTEVE BaRBA, op. cit., pp. 242-244.

69 Existe un estudio historiográfico sobre el P. Cavo realizado por Victor RICO GONZALEZ, en F. Esteve BARBA, op. cit., pp. 244-246.

70 Sacerdote de la Casa profesa de Lima, Provincia de Peń. Embarcado en Cartagena de Indias en la Urca real «San José» para La Habana donde llegó el 24-VI-1768. Datos proporcionados por el profesor Giménez. Véase también sobre el P. Larreta: Salud Moreno ALONSO, op. cit., pp. 197-202.

71 Sacerdote del Colegio de San Pablo de Perí. Nacido en Huancavelica en 1734. Jesuita desde 1751. Realizó su noviciado y la tercera probación en Cuzco; fue operario en Arequipa y en el Máximo en 1767. Embarcado en el navío «El Peruano». Se hallaba en el Puerto de Santa María en mayo de 1768. Desembarcado en La Spezia el 6 de agosto de 1768. Se secularizó el 20 de julio de 1768; en A.R.S.I. Residente en Roma en 1774, en A.G.S., D.G.T. Inventario 27, Leg. 1. Véase, también, sobre el P. Godoy el artículo de Guillermo FuRLONG, «Juan José Godoy, S.I. Precursor de la Independencia americanas, Revista de la Junta de Estudios Históricos de Mendoza, Mendoza, (1972), pp. 257-284.

$n$ Biblioteca de Florencia, N.A. 151, III.

${ }^{3}$ Nicholas CUSHNER, op. cit.

74 A.G.S., Estado, Leg. 5.047, Memorial de los novicios de la Compañta de Jesús.

75 Se encuentra manuscrita en A.H.P.C.T.S.I., M-28 (90, I.1).

${ }^{26}$ A.G.S., Dirección General del Tesoro, Inventario 27, Leg. 1.

7 Manuscrito en A.H.P.C.T.S.I., M-252 (1073).

${ }^{78}$ En FRIAAS, Lesmes, op. cit., p. XII.

Actas del I Congreso de Historia de la Iglesia y el Mundo Hispánico Hispania Sacra, 52 (20\%) 
Se dice que el P. José Sánchez Labrador, perteneciente a la Provincia de Paraguay, trató en un diario el viaje del destierro ${ }^{79}$, pero después de consultar en el segundo volumen de El Paraguay Católico, custodiado en la Real Academia de la Hisotria, hemos encontrado sólo diferentes diarios de misiones y ninguno del destierro. De la misma provincia, tenemos los apuntes del P. Florián Paucke, misionero que narró sus experiencias entre los indios mocobíes, con los que vivió, en la reducción de San Javier en el Chaco, desde 1750 hasta $1767^{80}$, fecha en la que embarcó en la fragata La Esmeralda desde el puerto de Buenos Aires. Pablo Hernández sitúa al P. Pauke en la Provincia de Santa Fe y sobre ese diario asegura que lo escribió sin apuntes y varios años después de su salida de América ${ }^{81}$.

El diario y el resto de los escritos de Peramás ${ }^{82}$, también perteneciente a la provincia paraguaya, fueron estudiados por Furlong en la obra referida. El diario responde, perfectamente, a la estructura e intenciones de todos los textos jesuíticos escritos en el exilio: comienza narrando la intimación de la expulsión a los jesuitas cordobeses en la madrugada del 12 de julio de 1767, continúa con la travesía hasta Cádiz, narra las vicisitudes por el Mediterráneo y finaliza cuando los expulsos se instalan en los Estados pontificios en 1769, sin abandonar el tono apologético presente en el relato. En el Archivo del Ministerio de Asuntos Exteriores de Madrid se encuentra una carta en italiano escrita por un jesuita espafiol expulso y, posteriormente secularizado, José Salvador de VargasMachuca ${ }^{83}$, en la que se censura este diario del P. Peramás y el relato escrito por el P. Alonso Pérez de Valdivia ${ }^{84}$, perteneciente a la Provincia de Andalucía, y al que nos hemos referido con anterioridad. Vargas-Manchuca criticaba ambos manuscritos tachándolos de partidistas, afirmando que estaban fundados en un

79 VV.AA., José Sánchez Labrador y los Naturalistas Jesuitas del Rto de la Plata, MOPU, Ávila, 1989 , p. 286, sobre la biografía de este autor véanse pp. 101 y ss.

* Paucke escribió su obra mientras estaba desterrado en Austria, y su título no tiene desperdicio: Hacia alld (fuimos) amenos y alegres, para acd (volvimos) amargados y entristecidos..., se conserva manuscrita en la biblioteca del monasterio cisterniense de Zwettl.

81 Pablo Hernandez, El extrañamiento de los jesuitas del Rio de la Plata y de las misiones del Paraguay por decreto de Carlos III, Madrid, 1908, p. 75. También KOBLER, P. Florián Baucke, ein Jesuit im Paraguay, cap. VI, I,.p. 616, Ratisbona, 1870.

82 Sobre el P. Peramás: Guillermo FurLoNG, José Peramás y su Diario del destierro (1768), Librerfa del Plata, Buenos Aires, 1952; E. GimÉnez y M. MARTtNez, «La llegada de los jesuitas expulsos a Italia segín los diarios de los padres Luengo y Peramásn, Relaciones Culturales entre Italia y España, Ed.: J. A. Ríos y E. Rubio, Universidad de Alicante, Alicante, 1995, pp. 63-77 y Pablo HeRNÁNDEZ, El extrañamiento de los jesuitas del Río de la Plata y de las misiones del Paraguay, Madrid, 1908, pp. 78 y ss.

s3 Sobre este jesuita: F. MEDNA, "Ocaso de una provincia de fundación ignaciana: la Provincia de Andalucía en el exilio (1767-1773)», Archivo Teológico granadino, 54 (1991), pp. 71-73.

${ }^{4}$ Aparece como Alfonso Pérez. 
espíritu ciego de defensa a ultranza de la Compañía. Asegura que él podía demostrar que aquellos manuscritos sólo contenían embustes y tergiversaciones, ya que había padecido junto a los diaristas el destierro y realizado el viaje hasta los Estados Pontificios y consideraba que el objetivo de ambos escritos era:

«que algún día salgan a la luz y cuenten una historia basada en testimonios personales y de gentes cualificadas, pero al mismo tiempo falsas y tergiversadas (...) estas serán las fuentes donde beberán los jesuitas para escribir su gloriosa historia, pero también será un documento lleno de calumnias donde la corte española será presentada como la culpablen ${ }^{85}$.

Al mismo tiempo, acusaba a los expulsos de querer manchar la imagen de los secularizados, y se proponía contradecir todos los comentarios de los que había sido testigo, para así dar a la Compañía un castigo similar al que recibió de Ibañez de Echarri en Paraguay ${ }^{86}$. Desde luego, interés puso, ya que dejó escritos a pie de página una serie de comentarios mucho más extensos que las propias descripciones del diarista andaluz, el P. Pérez. La corrección debió terminarse de 23 de abril de 1773, es decir dos días después de que Ganganelli firmase el breve de extinción de la Compañía de Jesús. Lo que podría justificar la poca proyección que tuvo.

El también paraguayo Francisco Iturri ${ }^{87}$, escribió, según Pablo Hernández ${ }^{88}$, un diario que sitúa en el Archivo de la Provincia de Toledo; pero puestos en contacto con el P. Torres, que lo custodia en la actualidad, nos confirma que no se localiza en ese Archivo. En la misma obra de Hernández, vuelve a nombrar el diario de Iturri y lo ubica en la Provincia de Castilla ${ }^{89}$. Ni el P. José Ramón Eguillor ni Olatz Berasategui, encargados del Archivo de Loyola, pudieron localizar este escrito, ni ningún otro realizado por este jesuita. Lo que sí sabemos es que escribió algunos memoriales a la corte de Madrid, el primero de ellos, dirigido a Godoy en octubre de 1796 , solicitando ayuda económica ${ }^{90}$, otro en el pide socorro para viajar a Buenos Aires en $1798^{91}$; y un tercero desde Roma, en diciembre de 1807 , en el que pide segunda pensión ${ }^{92}$.

${ }^{85}$ Archivo del Ministerio de Asuntos Exteriores (A.M.A.E.): Leg. 341: Prima Lettera sopra i giornale de Peramas-Alfonso Perez.

B6 Véase: G. FURLONG, «El expulso Bernardo Ibafiez de Echavarri y sus obras sobre las misiones del Paraguaym, Archivum Historicum Societatis lesu, 2, (1933), pp. 25-34.

87 Francisco de Borja Iturri pertenecía al Colegio de la Asunción de Paraguay en 1767, donde era sacerdote. Había nacido en 1738 y era jesuita desde 1753. En 1772 profesó el cuarto voto y, un afio más tarde, residía en Rávena. Datos facilitados por el profesor Giménez.

${ }^{88}$ P. HERNANDEZ, op. cit., p. 92 (1).

${ }^{89}$ H. P. HERNANDEZ, op. cil., p. 95.

90 A.G.S., Estado, Leg. 5.064.

91 A.G.S., Estado, Leg. 5.064

92 A.G.S. Estado, Leg. 5.065.

Actas del I Congreso de Historia de la Iglesia y el Mundo Hispánico Hispania Sacra, $52(2000)$ 
Acerca de los jesuitas chilenos se conservan dos cartas sobre el extrañamiento escritas por el P. Pedro Weingartner ${ }^{93}$, una -que permanece inédita--, fue escrita en 1769 y versa sobre la situación de los novicios; la otra, escrita en 1770 , relata los acontecimientos que ocurrieron durante su viaje. Ambas se encuentran en el archivo del Colegio de los Jesuitas de Munich. Y el novicio chileno, Juan Arqueiro Gómez ${ }^{94}$, nos relata en su diario, titulado Breve razón del viage que hicieron las Misiones de Chile y Paraguay a la América el año de $1767 \ldots{ }^{95}$, el tormentoso viaje que emprendieron hacia América varios de estos regulares dias antes de la intimación de la expulsión, su vuelta a Europa sin casi haber puesto pie en el continente americano y su exilio a Italia. También chileno era el jesuita que escribió una memoria que comenzaba con su llegada a la ciudad de Callao el 24 de febrero de 1769. Se trata de un escrito del sólo nos ha llegado una parte, falta el principio y el final, y en el que narraba lo acontecido durante el éxodo. En este manuscrito se describe el viaje que hicieron setenta jesuitas chilenos desde Callao hasta Lima, transportados en treinta y cinco coches y escoltados por soldados, así como su alojamiento en la que había sido Casa Profesa de Nuestra Señora de los Desamparados. En este colegio, que solía albergar a unos veintiseis regulares, llegaron a concentrarse más de doscientos expulsos a primeros de marzo de aquel año, hasta que, embarcaron en el navío «Santa Bárbara», hacia el exilio. El 29 de agosto de 1769, después de cinco meses y medio de travesía, divisaron la ermita de Nuestra Señora de Regla en Chipiona, a la que agradecieron que durante la travesía sólo hubiera perecido un jesuita. Es un escrito incompleto y anónimo, dirigido a un padre que había solicitado al autor constancia de su periplo $0^{96}$. Por otra parte, en Bolonia, en 1776, el P. Juan Ignacio Molina publicó el primer volúmen de su Compendio della storia naturale e civile del regno del Chili, mientras que el segundo salió en $1787^{97}$.

Como hemos visto, el hecho de que casi todas las Provincias de la Asistencia de España tengan, al menos, una relación nos mueve a pensar que fueron reali-

93 Pedro Weingartner Clasin nació en Baviera en 1721. Siendo sacerdote entró en la Compañía en Venecia en 1746. En Chile fue operario en el Máximo, misionero del obispado y operario en La Olleria. Volvió a Alemania en 1767. En Walter HaNIsCH, Itinerario y pensamiento de los jesuitas expulsos de Chile (1767-1815), Ed. Andrés Bello, Santiago de Chile, 1972, p. 324.

94 Juan Arqueiro aparece como autor de otros manuscritos en la segunda parte de la obra de J. E. URLARTE y M. LeCINA, Biblioteca de escritores de la Compañia de Jesús ..., Madrid, 1925.

95 El titulo completo es: Breve razón del viage que hicieron las Misiones de Chile y Paraguay a la América el año de 1767 y de la vuelta a España, y Paraguay a la América el año de 1767 y de la vuelta a España, y de lo que principalmente acaeció tanto a la ida, como a la vuelta, y últimamente del viage hecho desde España a Italia. M. LuENGo, Colección, T. III, pp. 1-22.

96 Archivum Romanum Societatis Iest, Fondo Jesuitico, 1385.

${ }_{97}$ F. Esteve BARBA, op. cit., pp. 622-626. 
zadas siguiendo órdenes superiores, y la cantidad de las copias existentes de algunas de estas narraciones constata el interés por conservarlas y la positiva valoración con la que contaron. Aunque algunos diarios responden a la necesidad de anotar lo ocurrido con puntualidad para un posterior uso o simple recuerdo, y están carentes de un estilo apologético o de comentarios reflexivos, la mayoría de estos escritos son fruto de un trabajo de reflexión realizado después de ocurrir los acontecimientos que narran. Poseen una intencionalidad manifiesta y sus juicios son siempre críticos con sus incriminadores y laudatorios para los jesuitas. Asimismo, varios de estos diaristas impulsaron y guardaron las narraciones de otros jesuitas, alentándoles a describir sus viajes y los recuerdos del destierro y custodiándo los originales o escribiendo copias para asegurar su conservación. Por ejemplo, el P. Luengo, además de copiar el Memorial que escribió el P. Isla, pidió al P. Arqueiro que dejara constancia escrita de su expulsión de Chile, del número y nombre de los que le acompañaban y custodió, entre su Colección, la relación del padre filipino Pedro Caseda. El ascendiente del $P$. Luengo, como maestro de novicios, quedó reiteradamente reflejado en los diarios que escribieron algunos de estos jóvenes mientras eran sus alumnos: Vicente Calvo, Manuel Arqueiro e Isidro Arévalo, son claros ejemplos. De la misma manera el P. Alonso Pérez, de la Provincia de Andalucía, además de escribir su propia narración, alentó al $P$. Bernardo Recio, perteneciente a la Provincia quitefia, para que escribiera una relación con los acontecimientos de su viaje a Italia, y la puso a buen recaudo entre su recopilación de papeles. Por su parte, el P. Juan de Velasco, perteneciente también a aquella Provincia americana, y autor de la Historia del Reino de Quito, elaboró cinco volúmenes que tituló Colección de poesias varias hechas por un ocioso en la ciudad de Faenza, en los que dejaba constancia de las obras de quince jesuitas quiteños ${ }^{98}$. Estos son algunos ejemplos de la importancia que dieron siempre los expulsos a estas memorias autógrafas, para suerte nuestra y temor de los comisarios reales que, en 1767, escribían desde Córcega: «... en lo relatibo a la conducta de los extrañados, no hai por ahora otra particularidad que la de estar secretamente algunos componiendo una relación de lo passado en su expulsión de España y destino de Córcega) ${ }^{99}$.

Hemos querido reseñar y comentar, brevemente, todos estos escritos para que se observe cómo el objetivo de todos ellos no fue otro que enaltecer a la Compañía de Jesús con el fin de que se escribiera una historia adecuadamente

98 En Nicholas CusHNer, Philippines Jesuits in exile, Rome, 1964.

99 A.G.S., Estado, Leg. 5.650. Luis Gnecco a Grimaldi, 20 de diciembre de 1767. En E. GiMćnez LOPEz y M. MARTtíez Goms, «Los diarios del exilio de los jesuitas de la Provincia de Andalucía» en Revista de Historia Moderna, Anales de la Universidad de Alicante, 13-14, (1995), pp. 211-254.

Actas del I Congreso de Historia de la Iglesia y el Mundo Hispánico

Hispania Sacra, $52(2000)$ 
benévola, en detrimento de las posturas regalistas que defendía la Corte espafiola. Para ello algunos superiores encargaron la redacción de memorias a miembros de todas las provincias, en ellas resaltan los hechos más ignominiosos contra los regulares. Éstos se sirvieron de la dura exposición de sus padecimientos -que fueron muchos-- durante los inevitables viajes que les reunieron en el exilio, de los altercados que tuvieron en las legacias de los Estados Pontificios y de su dilatado destierro, extrapolándolos en beneficio de la leyenda blanca que defendía la inocencia de la Compañía de Jesús. 